\title{
O cerceamento da atividade cultural por meio da legislação ambiental em Campo Grande, Mato Grosso do Sul, no ano de 2018
}

\author{
The suppression of cultural activity through environmental legislation in Campo \\ Grande, Mato Grosso do Sul, in 2018 \\ La reducción de la actividad cultural a través de la legislación ambiental en \\ Campo Grande, Mato Grosso do Sul, en 2018
}

\author{
João Paulo Abdo ${ }^{1}$ \\ Giselle Marques de Araújo ${ }^{1}$ \\ Ademir Kleber Morbeck de Oliveira ${ }^{1}$ \\ Recebido em: 13/04/2020; revisado e aprovado em: 03/11/2020; aceito em: 28/12/2020 \\ DOI: http://dx.doi.org/10.20435/inter.v22i3.3006
}

\begin{abstract}
Resumo: No ano de 2018, em Campo Grande, Mato Grosso do Sul, a Lei Municipal 2.909/92, conhecida popularmente como "Lei do Silêncio", sofreu alterações em seus dispositivos, de modo a restringir os limites sonoros de eventos culturais a 45 decibéis. Em consequência disso, espaços destinados à cultura foram fechados, por não conseguirem estar de acordo com as determinações legais para o funcionamento. Além do encerramento de atividades de locais que fomentavam a cultura independente e autoral, com ênfase na música, trabalhadores perderam também seus empregos. Desse modo, o presente estudo visa trazer à tona algumas das implicações que a alteração da lei trouxe à vida cultural da cidade e entender os conceitos música, arte e cultura dentro dessa legislação. Para isso, foram aplicadas entrevistas semiestruturadas, posteriormente analisadas na perspectiva de Bardin (2009), a produtores culturais no período em questão, além de análise documental e revisão de literatura complementar, a fim de se confirmar a hipótese de que a diminuição de decibéis proposta pela legislação ambiental é uma forma de desarticulação às manifestações culturais na cidade. Espera-se, com este trabalho, ampliar o debate acerca da importância cultural para o desenvolvimento social e ambiental, além de levantar informações que possam contribuir para definir conceitos inconsistentes na Lei.
\end{abstract}

Palavras-chave: cultura; música; Lei do Silêncio; restrição cultural.

Abstract: In 2018, in Campo Grande, Mato Grosso do Sul, the Municipal Law 2.909/92, commonly known as the "Lei do Silêncio" (noise control law), changed in its text to restrict the noise limits of cultural events to 45 decibels. As a result, cultural areas were closed because they could not be following legal requirements for operation. In addition to the shortage of places that fostered an independent and authorial culture, with an emphasis on music, workers also lost their jobs. Thus, the present study aims to bring to light the implications that the amendment of the Law brought to the cultural life of the city and to understand the concepts music, art and culture within this legislation. For this, we applied semi-structured interviews to cultural producers in the considered period. This information was later analyzed according to Bardin (2009). Documental analysis and literature review complementaries were also employed to confirm the hypothesis that the decibel reduction proposed by environmental legislation is a form of disarticulation to the cultural manifestations in the city. It is hoped, with this work, to broaden the debate on the cultural importance for social and environmental development and raise information that may contribute to define inconsistent concepts in the Law.

Keywords: culture; music; noise control law; cultural restriction.

Resumen: En 2018, en Campo Grande, Mato Grosso do Sul, la Ley Municipal 2.909/92, conocida popularmente como la "Lei do Silêncio" (legislación acústica), sufrió cambios en sus dispositivos para restringir los límites de sonido de los eventos culturales a 45 decibelios. Como resultado, los espacios destinados a la cultura se cerraron porque no podían estar de acuerdo con los requisitos legales para la operación. Además de la escasez de lugares que fomentaban la cultura independiente y autoral, con énfasis en la música, los trabajadores también perdieron sus empleos. Por lo tanto, el presente estudio tiene como objetivo sacar a la luz las implicaciones que la enmienda de la Ley trajo a la vida cultural de la ciudad y comprender los conceptos de música, arte y cultura dentro de esta legislación. Para ello, se aplicaron entrevistas semiestructuradas, analizadas según Bardin (2009), a productores culturales en el período en cuestión, así como análisis

\footnotetext{
${ }^{1}$ Anhanguera-UNIDERP, Campo Grande, Mato Grosso do Sul, Brasil.
} 
documental y revisión de literatura complementarios, para confirmar la hipótesis de que la reducción de decibelios propuesta por la legislación ambiental es una forma de desarticulación de las manifestaciones culturales en la ciudad. Se espera, con este trabajo, ampliar el debate sobre la importancia cultural para el desarrollo social y ambiental, así como generar información que pueda contribuir a definir conceptos inconsistentes en la Ley.

Palabras clave: cultura; música; legislación acústica; restricción cultural.

\section{INTRODUÇÃO}

Em Campo Grande, capital do estado de Mato Grosso do Sul, no ano de 1992, foi sancionada a Lei n. 2.909, que instituiu o Código de Polícia Administrativa do município. Segundo o capítulo III, ficou proibido perturbar o sossego e o bem-estar público com sons de qualquer natureza ultrapassando os limites definidos pela norma NBR 10.151 da Associação Brasileira de Normas Técnicas (ABNT). Para fins de aplicação da Lei, foi definido como período noturno o horário entre 21:00 e 6:00, com o limite máximo de 45 decibéis, em zonas residenciais; e 55 decibéis, em zonas comerciais e de serviços e zonas de transição.

Essa Lei foi sofrendo alterações em seus dispositivos, ora tornando-a mais flexível, ora tornando-a mais rígida. No dia 28 de março de 1996, surgiu a Lei complementar n. 8, que, entre outras alterações, abriu exceção para sons emitidos em ocasiões de festas tradicionais, como o Carnaval, Natal e Ano-Novo. Anos depois, em 31 de março de 2014, ocorreu uma nova alteração por meio da Lei Complementar n. 228, excluindo música, arte e cultura da categoria de ruído conceito esse definido como som que cause ou tenda a causar perturbações ao sossego público ou produzir efeitos psicológicos ou fisiológicos negativos em seres humanos e animais.

Em 2015, ocorreu outra flexibilização por meio da Lei Complementar 267, de 14 de agosto. Dessa vez, em locais de pouca densidade habitacional, atrações musicais e eventos artísticos em geral, com duração máxima de 8 horas, poderiam ocorrer desde que obedecessem aos limites de 95 e 90 decibéis, diurno e noturno, respectivamente.

No entanto essas mudanças que ocorreram entre 2014 e 2015 foram julgadas inconstitucionais, em março de 2018, pelo Tribunal de Justiça do Estado, a pedido do Ministério Público de Mato Grosso do Sul, nos autos da Ação Direta de Inconstitucionalidade n. 200002428.2016.8.12.0000. O argumento apresentado era de que a esfera municipal se sobrepôs à Resolução do Conselho Nacional do Meio Ambiente (CONAMA) n. 1/90, que trata especificamente sobre a emissão de ruídos provenientes de atividades sociais e recreativas, e da Resolução 2/90, a qual estabelece que os limites de emissão em nível estadual e municipal poderão ter valores mais rígidos com relação aos definidos pela União. O limite estabelecido para o funcionamento de bares e afins ficou em 45 decibéis (LEITE, 2018).

Logo após essa determinação judicial, foi noticiado pela mídia local o fechamento de diversos espaços culturais que fomentavam a vida noturna de Campo Grande com atrações artísticas, principalmente musicais, e que empregavam, direta e indiretamente, pessoas ligadas à cultura campo-grandense. Alguns desses locais eram também responsáveis por revitalizar regiões consideradas perigosas - a exemplo da Passarela Sylvio Cesco, no cruzamento da avenida Calógeras com a rua Antônio Maria Coelho, área central da cidade (ROCHA; CUNHA, 2018).

Em dezembro de 2018, houve uma audiência pública na Câmara Municipal de Campo Grande a fim de debater os impactos da Lei do Silêncio. Estavam presentes músicos, moradores, comerciantes e empresários. A audiência recebeu também representantes da Associação Brasileira 
de Bares e Restaurantes (ABRASEL), Associação Comercial e Industrial de Campo Grande (ACICG), Campo Grande Destination, Conselho Estadual de Turismo, Federação do Comércio de Bens, Serviços e Turismo (Fecomércio), Fórum de Cultura de Campo Grande e Ministério Público de Mato Grosso do Sul (MPMS), além de representantes da Prefeitura e Governo. Para o vereador João César Mattogrosso, o entrave na flexibilização da lei está no Plano Diretor da cidade, em que existem inconsistências acerca do zoneamento que estabelece onde é área residencial ou área mista (ROCHA; CUNHA, 2018).

Mas, além do zoneamento urbano, existem outros aspectos a serem considerados e que estão ligados à concepção de cultura. Para Chauí (1995a), pode-se entender cultura como o trabalho da sensibilidade, criatividade, inteligência e reflexão humana. Existe a necessidade de compreender que todos os cidadãos são sujeitos culturais, mesmo que não sejam diretamente criadores de obras de arte ou pensamento. Desse modo, a cultura deve ser democrática, cabendo a todos o direito à sua fruição, experimentação, memória e participação. A legislação ambiental deveria contemplar tais aspectos, e não reduzir as manifestações culturais aos limites da "emissão de ruídos".

Esse processo de democratização cultural deve se dar por meio do acesso a ambientes onde transitam formação, informação, reflexão crítica, lazer e solidariedade social - como escolas, oficinas de arte, cinemas, teatros, eventos musicais e de dança e centros culturais em geral (CHAUI, 1995a).

Nesse sentido, percebe-se que a cultura é de suma importância, pois suas ferramentas de intervenção geralmente se aproximam da subjetividade humana. Esta subjetividade é um componente fundamental da articulação ético-política capaz de promover uma revolução social e cultural, reorientando a produção de bens materiais e imateriais e reconciliando o crescimento econômico com as formas de desenvolvimento sustentável (VECCHIATTI, 2004).

Nessa perspectiva, o presente artigo objetivou trazer à tona algumas das implicações que a alteração da legislação trouxe à vida cultural da cidade de Campo Grande, além de entender os conceitos "música, arte e cultura" dentro desse regramento.

\section{MATERIAL E MÉTODOS}

Na primeira fase da pesquisa, foram realizadas a revisão bibliográfica e análise documental preliminar. Estas deram base fundamental para, na fase seguinte, construir-se o roteiro orientador das entrevistas semiestruturadas e, na sequência, a aplicação das entrevistas aos sujeitos selecionados: produtores culturais que tiveram seus espaços fechados, a fim de verificar se o encerramento das atividades ocorreu por possíveis influências da legislação.

O projeto foi submetido ao Comitê de Ética em Pesquisa (CEP), sendo aprovado em setembro de 2019, para que as entrevistas acontecessem de acordo com as diretrizes do Ministério da Saúde. Todos os entrevistados assinaram o Termo de Consentimento Livre e Esclarecido (TCLE), que oficializa sua participação voluntária.

A pesquisa se deu predominantemente de forma qualitativa e seguindo os critérios de inclusão do estudo, foi escolhido um grupo de entrevistados, sendo que três indivíduos desse grupo se dispuseram a participar. Os critérios para a escolha foram: atuar na produção cultural em Campo Grande no período em que houve alteração nos dispositivos da Lei do Silêncio (2018); ser proprietário de um espaço cultural que possa ter sofrido impactos diretos dessas alterações e maior de 18 anos; e desejar contribuir, por livre e espontânea vontade, para o desenvolvimento do estudo.

INTERAÇÕES, Campo Grande, MS, v. 22, n. 3, p. 789-802, jul./set. 2021. 
A análise das entrevistas, conforme Bardin (2009), utilizou a metodologia denominada Análise de Conteúdo. Ela consiste em três etapas: pré-análise, seguida de exploração do material e, por fim, tratamento dos resultados. Nelas se deu o encontro entre referencial teórico e dados da análise documental.

O material de análise consistiu nas entrevistas gravadas com posterior degravação, sendo aplicadas, degravadas e analisadas no mês de novembro de 2019, em Campo Grande, Mato Grosso do Sul.

Para a preservação da privacidade dos entrevistados, eles foram renomeados para " $A$ ", "B" e "C".

\section{RESULTADOS E DISCUSSÃO}

A cultura pode ser concebida com diferentes significados. Kant (2012) identificou no ser racional a cultura como a capacidade de escolher seus fins em geral e, portanto, de ser livre. Por isso, "só a cultura pode ser o fim último que a natureza tem condições de apresentar ao gênero humano" (KANT, 2012, p. 83). Marx (1988) buscou compreender a cultura nas suas vinculações com o modo de produção e, para além disso, Bourdieu (1979) identificou o "conformismo lógico" ou o "sentimento do seu lugar" como restrição à liberdade estética da classe trabalhadora, favorecendo um sentido arbitrário cultural dominante.

A música, nesse contexto, atuaria fortemente como classificador da hierarquia entre os indivíduos: "Não há nada tão poderoso quanto o gosto musical para classificar os indivíduos e por onde somos infalivelmente classificados" (BOURDIEU, 1979, p. 17). Segundo o mesmo autor, a classe dominante procura legitimar sua cultura como "a melhor", a que tem valor simbólico, e por isso detém o poder de acesso às informações.

Pelo conteúdo das respostas as entrevistas que foram aplicadas, veio à luz o fato de que os proprietários de estabelecimentos comerciais que lidavam com a execução de músicas não tão aceitas pelo circuito dito "comercial" (aquelas que estão tocando no rádio e tendo maior divulgação pela televisão) tiveram mais dificuldade em compreender os regramentos legais e as imposições do poder público. Esta situação revela grande dificuldade de acesso às informações referentes à legislação, confirmando-se assim a perspectiva de Bourdieu (1979), no sentido de que a arte pode estar sujeita a um fator arbitrário.

O privilégio de acesso ao conhecimento, quanto ao arcabouço jurídico que envolve os empreendimentos nos quais a música é executada, parece atuar como instrumento que torna legítimos determinados estilos musicais em detrimento de outros, que seriam menos aceitáveis. A liberdade à qual Kant (2012) se referiu, portanto, restaria comprometida ou até mesmo cerceada nesse cenário, onde a Lei do Silêncio pode ser invocada sempre que gêneros musicais ilegítimos, na perspectiva da classe dominante, ou simbolicamente menos importantes, estivessem sendo adotados por bares, restaurantes ou similares.

Desta maneira, levando-se em consideração os conceitos de Bourdieu (1979), Marx (1988) e Kant (2012), procedeu-se à análise do material coletado durante a aplicação dos questionários.

No momento em que foram realizadas as entrevistas, a média de idade dos entrevistados era de 36 anos, podendo ser considerados adultos jovens. Estes relataram que o perfil do público de seus espaços culturais era diversificado, composto por homens e mulheres, divididos em grupos como LGBTs, brancos, pardos e negros, entre outros, alternando-se grupos de jovens e pessoas de mais idade, de vários estilos e classes sociais, sem distinção. Por noite, os estabelecimentos 
dos produtores $\mathrm{A}$ e $\mathrm{C}$ chegaram a receber, no auge de seu funcionamento, cerca de 700 pessoas, sendo que, na casa de cultura do produtor B, um pouco menos, em torno de 300 frequentadores.

Com relação à fiscalização por parte do órgão ambiental nos estabelecimentos, o produtor A alegou nunca terem recebido presencialmente algum fiscal em nome da Secretaria Municipal de Meio Ambiente e Gestão Urbana (SEMADUR). Já o produtor B falou que, desde o começo, a fiscalização em seu espaço cultural se deu de forma injusta: "[...] na primeira multa, a justificativa foi de que não havia documentação necessária para exercer a atividade no local. Isso não passou de uma grande mentira, pois toda a documentação solicitada já estava em andamento...", explicou. Ele apontou também que a fiscalização agiu de maneira preconceituosa, não entrando no espaço, alegando "integridade física dos fiscalizadores". O produtor afirmou que, por conta de o estabelecimento receber os mais variados tipos de pessoas, inclusive grupos alvo de preconceito, os fiscais ficaram com medo de adentrar o recinto. Avaliando aquela situação como injusta, o produtor se negou a pagar a multa, entrando com ação judicial contra o órgão ambiental.

O produtor $\mathrm{C}$ contou que foi interditado quatro vezes, uma pela Polícia Civil e outras três pela SEMADUR. Essas interdições se deram, segundo ele, por conta de o processo de retirada do alvará ambiental para música ser muito extenso e sem garantia nenhuma de obtenção no final, tendo durado, segundo palavras do produtor, 1 ano e 8 meses:

O processo é extremamente longo, você não sabe quando dá entrada no processo legal para vincular música ao ambiente. É investido um bom dinheiro sem saber se vai dar certo. Não me lembro ao certo quanto investi, mas poderia ter comprado um carro.

Dessa maneira, de acordo com o produtor, o local continuava a funcionar com música, mesmo sem o alvará adequado, como forma de repúdio a tamanha burocracia para estar de acordo com a legislação ambiental. "[...] um ano e oito meses é muito tempo...", afirmou. Acrescentou ainda que, desde o primeiro momento, o investimento em um espaço cultural com música ao vivo é cerceado pelo poder público.

Todos os entrevistados disseram ter ocorrido demissão em massa dos funcionários de seus estabelecimentos por conta do fechamento dos espaços de cultura, gerando desemprego. Foram dezenas de empregos, diretos e indiretos, que se perderam, afetando a possibilidade de sobrevivência digna de diferentes famílias.

Além disto, os produtores perderam suas únicas fontes de renda com o encerramento de suas atividades. Artistas - sobretudo os músicos, outros produtores que faziam parceria com esses locais para a produção de eventos culturais, técnicos de som, porteiros, barmen, atendentes, profissionais de limpeza, seguranças e cozinheiros, entre outras categorias profissionais associadas, perderam seus ofícios abruptamente.

Dessa forma, houve também uma ruptura na expansão econômica do setor da cultura na cidade, sendo que, conforme explica Sachs (2005), essa expansão posiciona-se como uma frente significativa na batalha pela geração de empregos e promoção de estabelecimentos culturais de pequeno porte, que encontram neste setor grandes oportunidades. Entre estas, podem ser citadas a realização de concursos para artistas, com premiações, no sentido de constituir acervos que possam pertencer à memória local, além do estímulo às produções artístico-culturais independentes, atribuindo uma regularidade a elas, uma vez que vão dispor de espaços para exibição e/ou execução. 
Sobre as multas, o produtor A alegou que, em seu espaço, não houve: "[...] eles sempre iam [os fiscais] quando não estávamos no recinto, então nunca aconteceu de nos multarem. De certa maneira a gente driblava a fiscalização...".

O produtor B recebeu o total de cinco multas, três delas relacionadas ao fator ambiental, uma por atraso de pagamento de alvará de funcionamento e a última foi a interdição do local pelo Ministério Público de Mato Grosso do Sul, que culminou no fechamento do espaço. Essas multas, somadas, chegaram ao valor de dezessete mil reais.

O produtor $\mathrm{C}$ recebeu ao todo três multas no valor de oito mil reais cada uma. Todas as punições foram aplicadas pelo órgão ambiental com a justificativa de vincular som ao recinto ao vivo ou não. Em uma dessas situações, foi multado com o bar fechado, às 16 horas:

Me perguntaram se as máquinas de fliperama emitiam som, eu disse sim, sons de videogame. Em seguida, um dos fiscais viu um jukebox e apontou dizendo 'isso é uma máquina de música!'. Pediram para que eu a ligasse, foi inserida uma moeda e em seguida, foi selecionada a primeira música à vista. Me multaram num sábado à tarde com o bar fechado. Eles estavam atrás de outro evento que aconteceria no bar ao lado e aproveitaram a viagem me multando de forma abusiva.

Quando perguntados sobre a clareza e a completude acerca das adequações necessárias para o cumprimento da legislação colocadas pelo órgão, houve consenso nas respostas. O produtor A respondeu:

A cada semana se descobria algo novo. Um funcionário jogava para o outro, que jogava para o outro, e para o outro. Se você perguntasse sobre o que era necessário para se adequar a três pessoas diferentes do órgão ambiental, você obtinha três respostas diferentes. Eles próprios desconhecem a Lei.

Além disso, complementou:

Descobria-se adequações necessárias após a abertura do espaço, adequações essas que envolviam altos custos financeiros, sendo que isso não era dito ao abrir o estabelecimento. Ou seja, propositalmente a ideia era de encurralar o produtor cultural desde o primeiro momento. Nunca foi possível descobrir tudo que fosse realmente necessário para o funcionamento adequado do lugar.

Segundo o produtor B:

A cada momento surgia algo novo a ser feito, nunca nada estava bom para eles [órgão ambiental]. Parecia que dificultavam nossa vida de propósito para que não funcionássemos. Cada hora uma exigência diferente. Fiz alterações estruturais, gastei rios de dinheiro em isolamento acústico, contratei vários engenheiros ambientais, inclusive um deles por indicação da própria SEMADUR, nada disso adiantou.

Seguindo a linearidade das respostas acerca dessa questão, o entrevistado C explicou:

Você vai pagando, apresentando documentos, mas em nenhum momento eles falaram 'você deve fazer isso, isso e isso'. Apenas no final do processo, sem garantia de nada, você fica sabendo o que deve apresentar para se adequar, e receber o sim ou o não do órgão ambiental. Enquanto isso continua perdendo dinheiro.

No tocante ao conhecimento por parte dos produtores sobre a Lei do Silêncio, todos tinham ideia prévia de seus dispositivos. No entanto foram pegos de surpresa com a diminuição dos limites sonoros. Ao término das entrevistas, cravaram suas considerações finais acerca do 
que todos os acontecimentos aqui registrados representavam a cada um deles, as pessoas e sua relação com a cultura e a cidade de Campo Grande.

Para A, a Lei do Silêncio significou um completo absurdo:

Da mesma forma que as pessoas que moram numa cidade precisam de silêncio, elas também precisam de atividades culturais. Uma lei que impõe 45 decibéis determina limites de som inferiores ao de um automóvel quando passa na rua. Então pergunto, deveriam proibir os carros de passar na rua? Não! Jamais adotariam uma política dessas. Então por que impedir que um espaço cultural, que emite níveis sonoros inferiores ao som dos aglomerados de carros na rua, de existir? Para que serve essa lei, para quem? Cidadania é eu andar com meu carro?

Ele ainda afirmou que as pessoas precisam usufruir da cultura, pois ela é um direito de todo cidadão. Complementou que nunca foi interesse fazer barulho ou incomodar vizinhos. Sempre houve preocupação em isolar o estabelecimento para atender às adequações e funcionar dentro dos parâmetros legais.

O produtor B alegou que a Lei é muito prejudicial para a classe artística, as pessoas que necessitam de opções culturais e a cidade:

Em nenhum momento pensaram em nós. Sempre tivemos preocupação com a vizinhança, lá - em residências próximas ao estabelecimento, viviam algumas pessoas, tentávamos ao máximo apaziguar o som das apresentações culturais. Eu não tenho problema nenhum em respeitar o espaço alheio, mas 45 decibéis são inaceitáveis.

Ele contou que passado um ano dos acontecimentos, ainda continua e continuará endividado por mais quatro:

Estou tentando limpar meu nome para poder trabalhar, fazer meus projetos culturais, que é o que sei e o que gosto de fazer. A sorte é que tenho família para me ajudar nesse momento de crise financeira, caso contrário, não sei o que seria de mim.

Por fim, o produtor $\mathrm{C}$ completou dizendo que em nenhum momento foi inocente a ponto de não saber que poderia ser interditado e que entendia sobre a importância de o espaço ser seguro para as pessoas, e não um problema social. De acordo com o produtor, o principal objetivo de seu espaço cultural era facilitar o acesso das pessoas à arte, abrir caminho para os artistas e produtores parceiros. Ele afirmou:

Não há diferença na Lei entre barulho e manifestação artístico-cultural, é tudo no mesmo saco. A Lei do Silêncio coíbe diretamente a cultura em Campo Grande. Nenhum conhecido meu, que trabalha no mesmo ramo, conseguiu tirar a licença ambiental, todos ficam impossibilitados pela tamanha burocracia.

Para o produtor, as leis deveriam incentivar a projeção cultural da capital sul-matogrossense, tendo em vista que é uma cidade jovem ainda em processo de formação de identidade. Para Chauí (1995b), identidade é a condição para que definamos as coisas e então possamos conhecê-las mais precisa e profundamente, a partir de suas definições. Então, as políticas públicas deveriam orientar-se no sentido de promover a cultura local e não a colocar na mesma categoria de badernas ou aglomerações sem sentido, para justificar a falta de importância dada a ela.

Em virtude dos acontecimentos no ano de 2018, o entrevistado denunciou a prática intimidadora do poder público:

Não querem saber o que está tocando, ou quem está se apresentando, simplesmente acabam com as possibilidades. Sem palco nunca saberemos o que as pessoas estão confabulando. Se 
eu, empresário da noite, acessar o site do portal do empreendedor para tirar licença de venda de bebidas, eu consigo isso facilmente. Ou seja, você pode entupir uma pessoa, maior de 18 anos, de bebida alcoólica que estará amparado legalmente. Ela pode dormir na calçada, completamente acabada, que está tudo certo. Mas um alvará que te dê o direito de ligar uma caixa de som e um microfone e falar o que pensa, eu demorei um ano e oito meses no processo e não consegui. É um paradoxo venenoso.

E concluiu: "[...] a Lei do Silêncio, como ela é, não faz o menor sentido...".

Pouco antes do fechamento definitivo de um dos estabelecimentos, foi criado pelos produtores da casa, junto a outros empresários do ramo e artistas - principalmente músicos -, o movimento "45 Decibéis Não". Este movimento tinha o intuito promover um diálogo robusto acerca dos limites considerados severamente restritivos.

Foi criada uma página em rede social, para dar mais visibilidade à mobilização, além de abaixo-assinado, para dar consistência à ação social. De acordo com o manifesto, os limites dispostos por lei eram similares ao de "uma conversa em mesa durante uma reunião" (PIMENTA, 2018, p. 1).

De forma irônica, foi realizado ainda um festival, em que a principal atração era o cochicho do público até 45 decibéis (PIMENTA, 2018). A mobilização não foi suficiente para uma mudança concreta na situação, muito menos para manter o espaço de portas abertas, mas serviu para deixar clara a revolta e a indignação de toda a classe lesada pela ausência de lógica dos limites sonoros dispostos pela legislação ambiental.

Revolta e indignação claramente justificáveis perante o que ensina Sachs (2005), no que diz respeito às atividades artístico-culturais, em que estas poderiam ser amplamente encorajadas por todos os meios, inclusive e principalmente pelo poder público - que agiu de modo contrário. A utilização destes espaços culturais se trata de uma maneira extremamente positiva de usar o tempo de não trabalho das pessoas, de estimular a convivência sadia entre elas e de cimentar aspectos referentes à identidade campo-grandense.

Contudo ficou evidente, por meio da pesquisa, que os produtores donos dos estabelecimentos culturais desconhecem também a legislação em suas entrelinhas. O Sistema Municipal de Licenciamento e Controle Ambiental (SILAM), instituído pela Lei Municipal n. 3.612, de 30 de abril de 1999, estabelece que empreendimentos dessa natureza, produtores de emissões sonoras consideradas poluidoras, estão sujeitos a um rigoroso processo de licenciamento ambiental, para fins de regularização completa de funcionamento.

Este processo de licenciamento é dividido em três fases: Licença Prévia (LP), Licença de Instalação (LI) e Licença de Operação (LO). Durante a primeira fase, o empreendedor necessita protocolar o pedido de Licença Prévia, não estando autorizado a iniciar o empreendimento. Essa licença apenas atesta que o ponto é ambientalmente viável para o funcionamento, considerando a especificidade das atividades que ocorrerão no local.

Com a LP em mãos, o empreendedor deverá ingressar com o pedido de LI. (segunda fase do licenciamento ambiental); nesse momento, será necessário apresentar um projeto de engenharia com a adequação das instalações às exigências legais. Esse projeto será analisado pela SEMADUR, que poderá determinar ajustes, aprovar ou desaprovar a licença. A partir do momento que essa licença for concedida, os aprimoramentos estruturais poderão ter início ou, no caso de obra nova, poderá ser iniciada a construção. Importante destacar que licença de instalação e alvará de construção não se confundem. Ambos são necessários para o início das obras. 
Depois de concluída a segunda fase do processo, o empreendedor poderá requerer a emissão da LO, após comprovar ter edificado ou reformado conforme o projeto aprovado no âmbito da LI. Nesse caso, haverá necessidade de o órgão ambiental vistoriar o local, verificando se as fases anteriores ocorreram de acordo com as normas estabelecidas por ele. Em caso positivo, o empreendedor poderá ser autorizado a operar devidamente licenciado.

Mas em qualquer fase do processo de licenciamento, até mesmo nessa etapa final, o órgão ambiental poderá se negar a conceder a licença ambiental. Uma vez concedida, poderá cassá-la, se for descumprida qualquer uma de suas condicionantes, ou se for constatada a iminência de dano ambiental ou à saúde, conforme possibilita o disposto no artigo 19 da Resolução 237 do CONAMA:

Art. 19 - O órgão ambiental competente, mediante decisão motivada, poderá modificar os condicionantes e as medidas de controle e adequação, suspender ou cancelar uma licença expedida, quando ocorrer:

I- Violação ou inadequação de quaisquer condicionantes ou normas legais.

II- Omissão ou falsa descrição de informações relevantes que subsidiaram a expedição da licença.

III- Superveniência de graves riscos ambientais e de saúde.

Isso ocorre porque a natureza jurídica da licença ambiental, conforme a lição de Fiorillo (2003, p. 66), é de ato discricionário e não vinculado. No ato discricionário, o agente administrativo tem liberdade para decidir, há um espectro de escolha, enquanto no ato vinculado o agente deve apenas aplicar o que está na lei. Exemplificando: se o empreendedor comprovar ter cumprido todas as exigências para obter um "alvará" de construção, será obrigação da autoridade administrativa emiti-lo, pois se trata de ato vinculado. No caso da licença ambiental, mesmo que o empreendedor cumpra todas as exigências contidas na lei, o agente público poderá recusar-se a emiti-la.

A pesquisa demonstrou que essa discricionariedade pode ser determinante em relação à escolha pelo agente público daqueles empreendimentos que serão fiscalizados, levando-se em conta o perfil do público que frequenta o local, classe social, gêneros e estilo musical, havendo maior pressão sobre os locais ditos "alternativos", frequentados pelo público LGBT, artistas, sujeitos da classe trabalhadora e estudantes.

A impressão que fica é de que há uma forte carga de subjetividade na ação fiscalizatória do poder público, que acaba agindo de forma seletiva em relação às manifestações culturais, algumas das quais são toleradas, enquanto de outras se exige a sujeição aos rigores da lei.

Portanto é preciso enfrentar a contradição que se coloca, no sentido de a cultura significar o modo de ser dos humanos e necessitar ser tomada em forma de direito pelas pessoas que não conseguem exercer plenamente o seu ser cultural. No caso, essas pessoas são as pertencentes às classes populares, como a classe trabalhadora (CHAUÍ, 1992), também frequentadora dos espaços alternativos de cultura.

Ademais, os empreendedores parecem não estar cientes das exigências quanto ao processo de licenciamento ambiental, por motivos aqui elucidados através de seus relatos. É de suma importância que se busquem meios para divulgar essa legislação, por meio de boletins técnicos, por exemplo, dando suporte a fim de garantir que o direito à livre iniciativa, presente no artigo 170 da Constituição Federal, seja plenamente exercitado. 
Ultrapassando as questões relacionadas ao licenciamento ambiental, entende-se que algumas saídas poderiam ser viabilizadas para que ambas as partes chegassem a um consenso, e solucionado fosse o problema das emissões sonoras na cidade.

O diálogo, contudo, foi impossibilitado pela parte que detém as regras do jogo. Não houve aproximação, tampouco auxílio para a existência permanente desses lugares, que subsistiram de forma efêmera. Nem a pressão popular através da classe artística e associados foi suficiente para isso acontecer, o que novamente demonstra o caráter autoritário que a classe socialmente dominante tenta imprimir à arte, conforme alertou Bourdieu (1979), limitando o direito à sua fruição, experimentação, memória e participação, nas palavras de Chauí (1995a).

Sobre as saídas, um corredor cultural poderia ser uma delas, pois, em uma cidade com o tamanho de Campo Grande, o zoneamento das áreas ainda é inconsistente e surgem locais de cultura e lazer em meio às residências; é lúcido que isso não funciona, pois nenhum dos lados da moeda estará satisfeito, nem o morador nem o dono do estabelecimento.

Faz-se necessário um ponto estratégico para a realização desses eventos, a exemplo de outras capitais do país, como Curitiba, Belo Horizonte e São Paulo, que possuem alguns redutos próprios para o exercício da cultura, segregados das áreas residenciais. Desta maneira, as cidades demonstram sua efervescência cultural e suas tendências cosmopolitas, ao contrário de outras, provincianas e apegadas ao conservadorismo cultural.

Desse modo, subentende-se que há pouco interesse do poder público em atuar como um facilitador cultural na cidade. E, não havendo espaço para atividades culturais, esse vazio é ocupado por retrocessos ostentosos, como a violência urbana e o aumento da pobreza, que, segundo a Organização das Nações Unidas para a Educação, a Ciência e a Cultura (UNESCO, 2010), não ocorrem somente pela ausência de recursos financeiros, mas também pelo desconhecimento dos valores culturais, fundamentais para o processo de cidadania e civilizatório.

Não é de hoje que as instituições públicas se conservam no direito de reprimir as manifestações culturais, consideradas por elas subversivas. Pode-se tomar como exemplo a censura na época da Ditadura Militar.

Durante os anos de 1964 e 1968, os gêneros como teatro, música e cinema estavam em alta e eram utilizados pelos criadores de arte como ferramentas de contestação ao regime autoritário imposto. Nesse contexto, houve forte violência ao exercício da cultura popular, imposto pelo Ato Institucional n. 5 - Al-5, uma grande ferramenta de intimidação pelo medo, estritamente presente durante esse período de obscurantismo (OLIVEIRA; RESENDE, 2001).

Assim, entende-se que os movimentos de censura durante o período ditatorial no Brasil tinham como intuito claro desarticular as forças populares da cultura que estavam se consolidando, desde os anos 1930. Estas forças se instalavam como potenciais opositoras ao governo militar, passando por cima da condição de submissão e terror sofrida pelos artistas, intelectuais e boa parte da população comum, sobretudo os sujeitos mais vulneráveis ao ódio reacionário - negros, gays, mulheres, jovens estudantes e outros, por meio das mãos do Estado (FERNANDES, 2013).

É público e notório que os espaços que sofreram fiscalização mais frequente do poder público foram aqueles frequentados por essas minorias étnicas e raciais, em que os ritmos musicais mais executados são os provenientes e os consumidos pela classe composta por esses diversos tipos marginalizados socialmente. Neste grupo musical, pode-se citar como estilos predominantes: o samba, o rap, o rock and roll e o reggae. 
Não se tem notícia de fiscalização intensa em locais onde se executa música sem teor subversivo e/ou reflexivo, como o sertanejo universitário. Este ritmo musical é executado em determinados locais, como nos altos das grandes avenidas da cidade frequentadas pelas pessoas das classes abastadas, resultado de uma indústria cultural que, segundo Adorno e Horkheimer (1985), tem como objetivo, puramente, o lucro e a hegemonia do pensamento dominante, padronizando seus produtos e consumidores à lógica de mercado. Assim, fica subentendido que a fiscalização tem classe, cor e gênero.

Desse modo, torna-se evidente que a censura nunca deixou de existir, mesmo após o declínio do governo militar no Brasil. Entretanto agora ela não ocorre mais de forma clara, encontrando diferentes maneiras de se disfarçar, para continuar atuante em sua repressão ao que considera fora dos padrões vigentes.

A Lei do Silêncio é mais uma prova disso: a intimidação, o cerceamento e a repressão ao acesso aos direitos constitucionais, como o contido no inciso IX do artigo 5‥, que diz: "[...] é livre a expressão da atividade intelectual, artística, científica e de comunicação, independentemente de censura ou licença".

As instituições do governo se dizem amparadas por uma legislação que vigora protegida pela falsa premissa da garantia do bem-estar social, em flagrante violação às garantias constitucionais. Ou seja, é uma censura diferente, que opera por meio de dispositivos legais, e, se ela consta na lei, tende a se concluir que tal medida é positiva para o quadro social.

Este bem-estar social, no parágrafo anterior citado, segundo Ruud (1991), em seu livro "Música e Saúde", referência para a área de musicoterapia, está também ligado à fruição das artes e dos bens de cultura, podendo estes atuarem não somente como uma alternativa à fala ou forma de expressão, mas como provedores da saúde humana.

Como exemplo de segmento artístico-cultural, pode-se citar a música, ponto central da discussão do estudo. Em geral, ela pode aumentar o bem-estar social, relaxando, estimulando o pensamento crítico das pessoas, propiciando consolo e calma em situações difíceis e tornando os indivíduos motivados para desenvolverem as atividades do dia a dia, como trabalhar, estudar, exercitar o corpo e a mente, entre outras (RUUD, 1991).

Pode-se dizer que arte e cultura são também fundamentais no sentido de promoverem mais que prazer, sentimentos de catarse associados à experiência de vida de cada ser ou reflexões. Estas aquecem a alma e, também, positivamente, o cenário econômico, podendo viabilizar a exportação de produtos culturais para outros países, obtendo retornos em forma de recursos, os quais, se devidamente aplicados, têm o potencial de gerar desenvolvimento para as cidades, sobretudo no setor da cultura.

Este setor é de grande importância, pois vai além do fomento econômico, contribuindo também para a consolidação identitária do país, para o estímulo à autoconfiança - individual e no âmbito de sociedade -, fundamentais ao modo de vida das pessoas e ao desenvolvimento de cada cidadão (SACHS, 2005).

As alterações legislativas no âmbito do Município de Campo Grande caminham na direção contrária da Declaração do Milênio da ONU (2000), que coloca a tolerância cultural como um valor fundamental e essencial para o desenvolvimento, "[...] como um precioso patrimônio da humanidade" (item 6.d). Além disso, violam o disposto no artigo 23, V, da Constituição Federal, que atribui à União, aos Estados, ao Distrito Federal e aos Municípios a competência comum para proporcionar os meios de acesso à cultura, à educação, à ciência, à tecnologia, à pesquisa e à inovação. 


\section{CONSIDERAÇÕES FINAIS}

O contexto no qual foi concebida a Constituição que está em vigor no Brasil era de abertura democrática. O povo estava mobilizado nas ruas, por meio de passeatas e comícios, pedindo o fim da ditadura e o direito de escolher sua própria representação política. Nesse clima, a cultura ganhou espaço em vários dispositivos, entre os quais o parágrafo único do artigo 4으, que atribuiu à República Federativa do Brasil a busca pela integração política, econômica e cultural dos povos da América Latina, visando à formação de uma comunidade latino-americana de nações.

No artigo 5으, inciso LXXIII, os cidadãos conquistaram legitimidade para propor ações que visem anular ato lesivo ao patrimônio cultural, e, no artigo 23, V, a Constituição atribuiu às esferas estatais o dever de meios de acesso à cultura. A despeito disso, o Estado pode estar sendo utilizado como instrumento de cerceamento do acesso às manifestações artísticas, conforme se revelou no âmbito desta pesquisa.

Isso ocorre especialmente quando determinados estilos musicais não são aceitos como legítimos, sob a perspectiva da classe dominante, ideia presente no referencial teórico construído a partir do pensamento de Bourdieu (1979), Marx (1988) e Kant (2012), que serviu como instrumental de análise.

No Brasil, país de leis obsoletas, em que determinações estaduais e municipais podem ser ainda mais esdrúxulas que as de esfera federal, não surpreende que um conjunto de normas com incongruências em face da Constituição Federal, como é o caso da Lei do Silêncio, estejam em pleno vigor sem nenhum revés.

Pouco a pouco, locais onde poderia circular cultura desaparecem subitamente e, com eles, a qualidade de vida das pessoas e do ambiente, a fonte de renda de famílias e a transmissão de consciência social atrelada às manifestações culturais.

Com as restrições às manifestações culturais que contribuam no processo de construção da identidade local, a revitalização e ocupação de regiões abandonadas pela administração pública na cidade naufragam no mesmo barco.

Durante a produção deste artigo, mais um espaço foi interditado por não conseguir atender às determinações legais, reforçando a percepção que se tornou evidente no decorrer desta pesquisa, no sentido de que as exigências legais não estão claras, dificultando e até mesmo impedindo a livre iniciativa de empreendimentos de cultura e o livre florescimento da diversidade cultural.

A falta de acesso às informações para o funcionamento dos estabelecimentos que executam músicas não tão aceitas pelos circuitos comerciais pode ser um instrumento que limita essa diversidade. Além disto, viola também o disposto no artigo primeiro da Constituição Federal, que deixa clara a opção do modelo de organização social do país, enquanto Estado Democrático de Direito.

Conforme a lição de Chauí (1995a), o acesso a ambientes onde transitam formação, informação, reflexão crítica, lazer e solidariedade social - como escolas, oficinas de arte, cinemas, teatros, eventos musicais e de dança e centros culturais em geral - é importante fator de democratização cultural. A Lei do Silêncio em Campo Grande, ao tratar a execução musical como "ruído", caminha na contramão dessa diretiva, que, afinal, é uma conquista da cidadania brasileira. 


\section{REFERÊNCIAS}

ADORNO, Theodor; HORKHEIMER, Max. Dialética do esclarecimento: fragmentos filosóficos. Rio de Janeiro: Jorge Zahar, 1985.

BARDIN, Laurence. Análise de conteúdo. Lisboa: Edições 70; LDA, 2009.

BOURDIEU, Pierre. La distinction: critique social du jugement. Paris: Minuit, 1979.

CHAUÍ, Marilena de Souza. Cultura política e política cultural. Estudos Avançados, São Paulo, v. 9, n. 23, p. 71-84, 1995a.

CHAUÍ, Marilena de Souza. Convite à filosofia. São Paulo: Ática: 1995b.

CHAUÍ, Marilena de Souza. Política cultural, cultura política e patrimônio histórico. In: CUNHA, Maria Clementina Pereira (Org.). Direito à memória: patrimônio histórico e cidadania em São Paulo. São Paulo: Departamento de Patrimônio Histórico, 1992. p. 37-46.

FERNANDES, Natalia Aparecida Morato. A política cultural à época da ditadura militar. ContemporâneaRevista de Sociologia da UFSCar, São Carlos, v. 3, n. 1, p. 173-92, 2013.

FIORILLO, Celso Antonio Pacheco. Curso de direito ambiental brasileiro. 4. ed. São Paulo: Saraiva, 2003.

KANT, Immanuel. Crítica da faculdade do juízo. [Kritik der urteilskraft und schrift em]. 3. ed. Tradução de Antônio Marques e Valério Rohden. São Paulo: Forense Universitária, 2012.

LEITE, Ana Paula. A pedido do MPMS, TJMS declara inconstitucional normas do Município de Campo Grande sobre poluição sonora. Ministério Público do Mato Grosso do Sul, Campo Grande, MS, 3 de abril de 2018. Seção Notícias. Disponível em: https://www.mpms.mp.br/noticias/2018/04/a-pedido-do-mpmstjms-declara-inconstitucional-normas-do-municipio-de-campo-grande-sobre-poluicao-sonora. Acesso em: 13 mar. 2019.

MARX, Karl. O capital: crítica da economia política. Tradução de Reginaldo Sant'Anna. 12. ed. Rio de Janeiro: Bertrand do Brasil, 1988. T. 1, v. 1.

OLIVEIRA, Eliane Braga; RESENDE, Maria Esperança. A censura de diversões públicas no Brasil durante o regime militar. Dimensões, Espírito Santo, v. 12, [s.n.], p. 150-61, 2001.

ORGANIZAÇÃO DAS NAÇÕES UNIDAS [ONU]. Declaração do Milênio das Nações Unidas - 8 de setembro de 2000. Biblioteca Virtual em Saúde do Ministério da Saúde - BVS MS. ONU, 2000. Disponível em: http:// bvsms.saude.gov.br/bvs/publicacoes/declaracao_milenio_nacoes_unidas.pdf. Acesso em: 3 fev. 2020.

ORGANIZAÇÃO DAS NAÇÕES UNIDAS PARA A EDUCAÇÃO, A CIÊNCIA E A CULTURA [UNESCO]. Relatório Unesco sobre a Ciência: 2010. Brasília: Unesco, 2010. 55 p.

PIMENTA, Thaís. Pelo direito de subir o volume do som, bar protesta com "festival de cochichos". Campo Grande News, Campo Grande, MS, 18 de agosto de 2018. Seção Diversão. Disponível em: https://www. campograndenews.com.br/lado-b/diversao/pelo-direito-de-subir-o-volume-do-som-bar-protesta-comfestival-de-cochichos. Acesso em: 3 nov. 2019.

ROCHA, Mylena; CUNHA, Maisse. Lei do Silêncio: em audiência na Câmara, 'barulho' de bares divide opinião de empresários e moradores. Midiamax, Campo Grande, MS, 17 de dezembro de 2018. Seção Cotidiano. Disponível em: https://www.midiamax.com.br/cotidiano/2018/campo-grandenses-lotamcamara-de-vereadores-para-pedir-mudancas-na-lei-do-silencio/. Acesso em: 13 mar. 2019. 
RUUD, Even. Música e saúde. 2. ed. São Paulo: Summus Editorial, 1991.

SACHS, Ignacy. Desenvolvimento e cultura. Desenvolvimento da cultura. Cultura do desenvolvimento. Organização e Sociedade, Salvador, v. 12, n. 33, p. 151-65, 2005.

VECCHIATTI, Karin. Três fases rumo ao desenvolvimento sustentável: do reducionismo à valorização da cultura. São Paulo Perspectiva, São Paulo, v. 18, n. 3, p. 90-95, 2004.

\section{Sobre os autores:}

João Paulo Abdo: Mestre em Meio Ambiente e Desenvolvimento Regional pela Anhanguera-UNIDERP. Músico e produtor cultural. E-mail: joaopabdo@gmail.com, Orcid: http://orcid.org/0000-0003-1535-8112

Giselle Marques de Araújo: Doutora em Direito pela Universidade Veiga de Almeida. Advogada e professora-pesquisadora do Programa de Pós-Graduação em Meio Ambiente e Desenvolvimento Regional na Anhanguera-UNIDERP. E-mail: giselle_marques@hotmail.com, Orcid: http://orcid.org/0000-0002-7083-1411

Ademir Kleber Morbeck de Oliveira: Doutor em Ecologia e Recursos Naturais pela Universidade Federal de São Carlos (UFSCAR). Professor-pesquisador do Programa de PósGraduação em Meio Ambiente e Desenvolvimento Regional na Anhanguera-UNIDERP. E-mail: akmorbeckoliveira@gmail.com, Orcid: http://orcid.org/0000-0001-9373-9573 